\title{
Who's policing whom? A look into the policing responses to harmful practices and the role of civic society
}

\author{
Polly Harrar
}

\begin{abstract}
The United Nations defines harmful practices as: ' . . persistent practices and behaviours grounded on discrimination on the basis of sex, gender and age and other grounds as well as multiple and/or intersecting forms of discrimination that often involve violence and cause physical and/or psychological harm or suffering'. They are commonly perceived to be based on tradition, culture, custom and practice, religion and/or superstition, and in certain communities and societies these practices have been established for so long that they are considered or perceived to be part of accepted cultural norms. Where they have gone unchallenged for multiple generations, they have become 'normalised', which often makes it difficult to make the distinction between cultural/traditional norms and enforced harmful and controlling behaviour. Examples of harmful practices include, but are not limited to, female genital mutilation, honour-based abuse, forced marriage, dowry violence and abuse linked to faith and belief, such as witchcraft, possessions and breast ironing - all of which are practiced and are prevalent in the UK today. The focus of this paper is honour based abuse (HBA), which is often applied as a precursor to other harmful practices and which lends itself to highlighting the intersectionality of this largely gendered practice. The role of affected communities is explored, as is how this can lead to a culture of self-policing. A panoptic framework is adopted before conclusions are drawn as to the future of policing in addressing these hidden harms. The aim of this paper is not to provide a comprehensive critical analysis of policing responses to an ever evolving and highly complex crime type, nor is it to present all BAME women and communities as a homogeneous group, but rather to further explore some of the key concepts that arose from discussions and which may go some way to understanding hidden harms that exist in relation to honour and shame.
\end{abstract}

\section{Introduction}

It is important to acknowledge the emergence of harmful practices, as they are multidimensional and involve enforced, stereotyped, gender-based roles. There is a perception of presumed superiority of males and inferiority of females in an attempt to exert control over the bodies and sexuality of women and girls through enforced social inequalities and maintaining male-dominated power structures. Indeed, international human rights treaties recognise violence against women and girls as a cause and consequence of women's inequality, which transcends all cultures, nationalities, faith groups and communities. Whilst not a new concept, the term honour violence, or honour based abuse, remains widely contentious amongst academics, researchers, practitioners and the UK Government. This is, in part, due to the view that using such terms lends itself to creating a separatist paradigm of 'them' being from practicing communities and 'us' being British society as a whole. In doing so it distinguishes this abuse type as being informed by religion, culture or tradition instead of addressing it for what it really is - violence against women or gender-based abuse. Debates and consultations continue to exist as to changing the terminology to reflect a universal consensus that there is no honour in honour based abuse, however, it is of less significance what professionals or 
Ministers feel this should be called, but more so what victims/survivors relate to in order to acknowledge, report and seek support.

Equally, perpetrators will justify their actions based on the [honour] values they place on their actions. As such, the impact of changing the name to suit 'others' does not reflect the language and experiences of affected communities, and gives rise to further criticism of applying a 'westernised' lens in identifying responses to harms that are largely practised, though not exclusively, from 'non-westernised' backgrounds (Le Roux et al, 2017). As such, there is always a danger that doing so will overly simplify what is already a highly complex and non-heterogenous concept (Wodon et al, 2020). Importantly, the focus should remain on tackling this form of abuse rather than on discussions as to the legitimacy of terminology. Practical consideration is also required, as institutional and legislative changes would be required to amend every reference to honour based abuse (HBA) with the judicial system, police flagging protocols, training and communications. It can be argued that this time and resource is best spent on supporting victims and survivors, and less so on appeasing perceived cultural correctness. Unlike other forms of harmful practices, HBA is not, in itself, a criminal offence in the UK, however it is recognised as an aggravated factor in what is often referred to as the 'A-Z' of crimes that are often applied to victims and survivors of HBA, such as abduction, kidnap, assault, child abuse, coercive control, domestic abuse, FGM, forced marriage, false imprisonment, stalking/harassment, neglect, theft [of passports/dowry], rape, sexual assault (forced pregnancy), suicide (accident) and murder in the name of [so called] 'honour'.

Whilst in western societies the term honour widely reflects a sense of pride and showing of respect to someone or something based on courageous achievements, actions or beliefs, in a cultural context, the notion of 'honour' broadly refers to a collection of beliefs and practices that are used to control behaviours in order to protect or maintain the positive status of a family or community, and is something that must be upheld at all times in order to be 'validated' and be viewed as 'respectable'. Failure to do so can result in 'bringing shame' or being ostracised/disowned, and can lead to perceived justification of actions to remedy or restore the 'honour' at all costs. The National Police Chiefs Council (NPCC) define HBA as

An incident or crime involving violence, threats of violence, intimidation, coercion or abuse (including psychological, physical, sexual, financial or emotional abuse), which has or may have been committed to protect or defend the honour of an individual, family and or community for alleged or perceived breaches of the family and/or community's code of behaviour.

Extensive research, studies and reports exist on the correlation between racial bias and policing in respect of using law enforcement techniques such as stop and search. Equally there is an acknowledgement that ethnic profiling is both problematic and controversial, particularly when used as a lever to legitimise the use of force and/or disproportionate policing of certain communities, as demonstrated through the Black Lives Matter movement. Yet, there remains limited investment and interest in research and studies as to the origins and causation of crime types that significantly affect black, Asian and minority women, such as harmful practices. However, there is an emerging rational amongst practitioners for applying 'race' to better understand communities' responses to gendered crimes, and to determine the risks faced by women and girls where breaches, or perceived breaches, of unwritten codes of behaviour are enforced through implied expectations and awareness of expected consequences for non-conformism. To a large extent, this has been useful for training purposes, introducing the one chance rule and in encouraging professional curiosity to ensure culture is not viewed as an excuse for abuse. In doing so it seeks to address the sometimes fragile balance between cultural understanding and reinforcing unconscious bias associated with BAME communities. 
Vol. 8, No. 1, 81-90.

\section{Policing response to harmful practices}

Whilst policing responses to HBA have arguably improved over the years, there remain many lessons to be learnt and, importantly, applied at operational, tactical and strategic levels. Forces have developed a toolkit of resources, which include applying legislative powers and protection orders (Sentencing - Ancillary Orders, 2019) with criminalisation for breaches applied and international jurisdiction (FMPO's), crime harm indexes to inform perpetrator profiling (multiple offenders), witness protection and safeguarding protocols, communityled intelligence and covert surveillance investment by some forces of HBA assessment toolkits developed by NGOs.

One criticism centred around the application of protection orders (FMPO's and FGMPO's) is the lack of monitoring and protective measures available once court proceedings have drawn to a close. Once an Order has been issued, in essence the victim/survivor is often placed back in the same environment with those named on the Order to self-manage the identified risks behind closed doors. In many cases, the protection orders are not directed to the relevant police force and, due to social mobility, there is a lack of tracking to better understand not only how many orders are issued but also in the identification of the protected parties. But it is through the partnership approach with subject matter experts and charities that policing has made significant strides in the furtherance of their understanding of hidden harms and influenced the development and need for training (Rosenbaum, 2002).

Indeed, the HMICFS 2015 inspection of the police response to honour based violence, forced marriage and female genital mutilation resulted in the publication of 'The depths of dishonour: Hidden voices and shameful crimes' report. This was the first time all 43 forces were inspected in relation to harmful practices and, whilst the findings were less than adequate, it called for the National Police Chiefs Council (NPCC) and College of Policing to work together and actualise the report's recommendations, and acknowledged the role of public sector agencies and international law enforcers to identify and safeguard victims and survivors. Moreover, the NPCC portfolio led to the appointment of regional and national policing leads responsible for eradicating honour based abuse, forced marriage and female genital mutilation; the development of the NPCC/CPS protocols and HBA Stakeholder

\section{Honour Based Abuse, Forced Marriage and Female Genital Mutilation} Delivery Plan for England, Wales and Northern Ireland 2018 - 2021

The UK Government \& Policing Structure

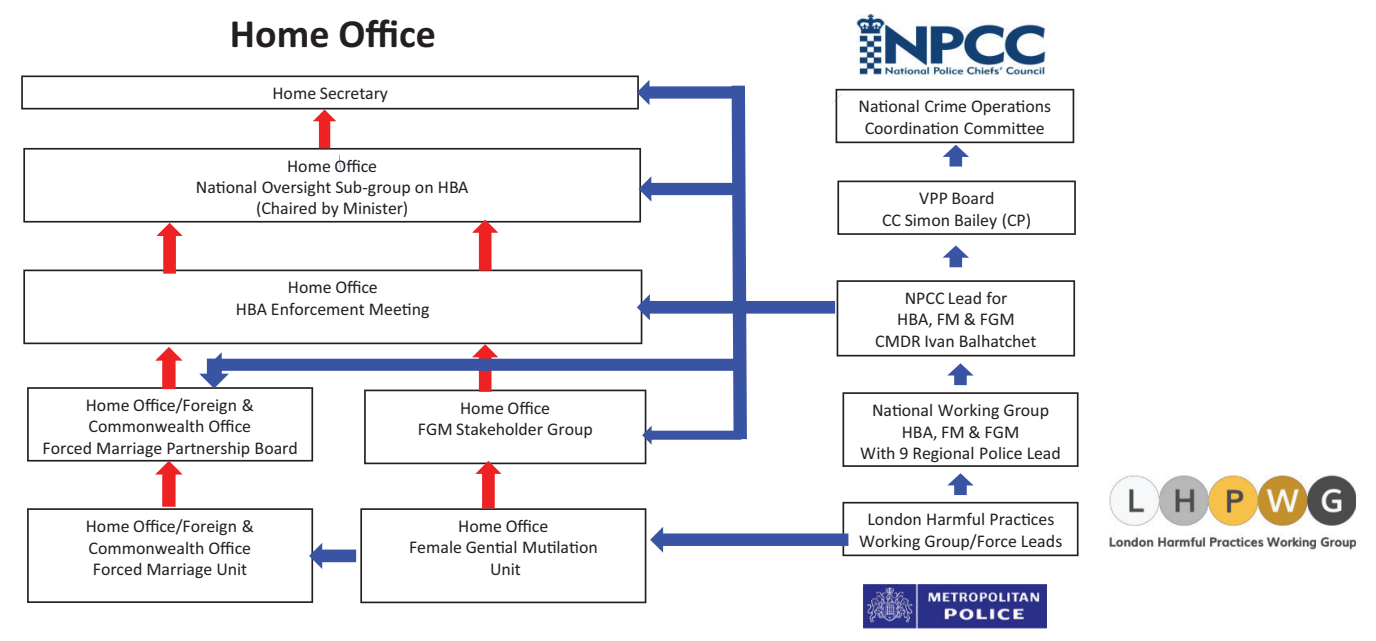

Figure 1 The UK Government and Policing Structure 
groups; and the creation of the London Harmful Practices Working group, co-led by the Metropolitan Police Service and a network of specialist stakeholders, NGOs and experts. All these feed into wider policing and government priorities in recognition of the need to address harmful practices at all levels of policing.

The use of technology in safeguarding is an established method; during the pandemic we have seen the value of this approach, particularly in cases of domestic abuse (which includes harmful practices). The Home Office's You Are Not Alone campaign went some way to reinforce the government's commitment to addressing domestic abuse, however it has been criticised for not going further to reflect the experiences of women and girls from BAME communities. Equally, the use of online apps and online chat forums have emerged in response to the lack of access to support during the pandemic, but these too acknowledge the lack of resources available to BAME communities due to social, political and economic limitations.

In January 2021 Commander Ivan Balhatchet, NPCC lead for FM, HBA and FGM, announced the implementation of the NTT Data Intelligence Model (Justice and Safeguarding at NTT DATA, 2021). Whilst a very new application, it is powered by Microsoft technology and delivered in partnership with the Police ICT and Ministry of Justice to ensure a more effective and efficient policing approach to harmful practices. As an intelligent safeguarding solution, it aims to ensure FMPO's and FGMPO's are automatically directed from the courts to the designated police force in minutes and, in doing so, it further removes the onus on vulnerable applicants to notify the police and allows for immediate safeguarding actions to be applied. It is too early to say how effective the NTT approach will be, however, it is a welcome move and one that recognises the need to monitor and safeguard those affected by these high risk crimes.

\section{Case study: Banaz Mahmod}

Banaz Mahmod disappeared from her South London home in January 2006 and her body was found in the West Midlands three months later. Her father and uncle were convicted of her murder in June 2007 following a trial at the Old Bailey. She was murdered by assassins hired by her father and uncle because she was seeing a man her father considered unsuitable. Banaz Mahmod repeatedly reported to the police that threats to kill had been made against her. Banaz went to the police on five separate occasions to report fears due to the honour codes that operated within her community, on one occasion, she even handed the police a note whereupon she wrote the names of the men (who would later be charged with her murder) that she knew would take her life. Following the Independent Police Complaints Commission (IPCC) investigation into the MPS and West Midlands police dealings with Banaz, the IPCC investigation found that: 'the MPS could have done more in its dealings with Ms Mahmod, lines of enquiry were not followed and there was poor supervision' ('Police "let down" honour killing victim', 20o8).

The IPCC investigation also found that: 'the initial investigation conducted by West Midlands Police was flawed, not done in a timely fashion and poorly supervised' ('Police "let down” honour killing victim', 2008). Nicola Williams, IPCC Commissioner said: 'Banaz Mahmod was let down by the service she received. There were delays in investigations, poor supervision, a lack of understanding and insensitivity' ('Police "let down" honour killing victim', 2008). The case of Banaz Mahmod highlighted the absolute need to ensure policing responses reflects the devastating impacts of harmful practices, and also reminds us that, whilst the police have come some way in better understanding these hidden harms, lessons still need to be learnt and applied. Not only was Banaz inexcusably failed by multiple police forces, she was failed by a community, who not only built an impenetrable wall of silence but actively went out of their way to impede the investigation by coming forward to give false alibis, provide misinformation and, disturbingly, remaining resolute of the view that Banaz's fate was justified, wearing their involvement in her demise as a badge of 'honour'. 
Vol. 8, No. 1, 81-90.

\section{The role of the community}

For the purpose of this paper, I am using a definition of 'community' adapted from the FAO conservation Guide to mean 'a collective of individuals and groups residing in a defined geographic locality, where similar cultural values are shared and where organisational structures and social bodies are determined towards the need to maintain unity and belonging in furtherance of establishing a security network based on moral behaviours' ('Inquiry meets with BAME women organisations to promote the Truth Project', 2017). Migrants have long established communities in the UK, in part to preserve a sense of tradition based on their cultural or religious roots, but also to ensure their survival in a new environment. This is often developed to create a sense of belonging, acceptance and protection; however, some communities remain closed to outsiders, which further perpetuates a sense of difference or 'other', particularly where integration with wider communities with 'western' values are rejected, prohibited or feared. Yet not all communities operate in a way that is harmful and many embrace wider social values to coexist and thrive quite successfully.

When looking at communities where honour codes are applied, cases of HBA often involve multiple perpetrators who are highly motivated and are well protected by others within the same or similar communities. This is why honour based abuse is often viewed as a form of serious organised crime, where a 'council' is appointed to act as judge and jury, and dispense justice as they see fit. In the case of Banaz, her fate lay at the hands of her father, her uncle, male relatives and members of the community, lending itself to view the role of male dominance as 'protectors' of the wider community. After all, if autonomy of choice, freedom and independence was permitted for one, who is to say that others would not wish to do the same, which, in turn could weaken the power structures held through the (often self) appointment of 'community leaders'.

\section{Self and alternative policing}

In an interview with The Times in 2014, the Chief Inspector of Constabulary, Sir Tom Winsor, stated that 'Parts of Britain are operating their own forms of justice as some minority communities take the law into their own hands' (The Huffington Post, 2014). He was referring to the practice of alternative policing by communities who hold the view that the role of policing is intrusive or obsolete towards the needs and understanding of their communities. He went on to say that the 'police are never called by certain minority communities because they [communities] administer their own justice even in cases as serious as murder and sexual assaults on children' (The Huffington Post, 2014).

This correlates to reports of [so called] honour based abuse and where taboos attached to child sexual abuse and incest continue to attract the need for preservation of honour above the needs of the victim(s) (Independent Inquiry into Child Sexual Abuse, 2017). Winsor told the newspaper that police were never called to some neighbourhoods as they 'administer their own form of justice', stressing that these 'alternative' systems were run not by criminals but by 'law-abiding people', which is important to note as the perception of perpetrators of HBA is often misunderstood (The Huffington Post, 2014). HBA largely involves a premediated, planned and collusive response to mitigate risk of 'dishonour' (perceived or actual), but perpetrators are often not known to services, as they have no previous criminal record and are well versed in portraying themselves as modern, liberal, nurturing and upstanding members of society. This makes perpetrators of HBA no less dangerous, as the perception of upstanding, law abiding citizens lends itself to keeping these harms hidden and unchallenged. Commentary from outside the 'community' is often viewed with suspicion and scepticism, as statements made by 'others' can be viewed as an attack on the community as a whole, making it difficult to address harmful behaviours that exist in all communities. 
When the former Home Secretary Jack Straw, in 2011, was accused of 'stereotyping' for suggesting some men of Pakistani origin see white girls as 'easy meat' the Judge responsible for the Derby case suggested that this was 'coincidental' (BBC, 2011) and, upon passing sentence, believed this was 'not a racial crime, but it is the latest in a series of criminal cases involving Asian men and young girls' (Reuters, 2011). Whilst Straw acknowledged that the majority of sex offenders were white men, it can be inferred that Straw attempted to address the notion of honour in stating that where Pakistani girls were 'off limits' and there was an expectation to marry a girl from Pakistan, young Pakistani men would 'seek other avenues'. However, Straw's comments were criticised by MPs and community leaders who claimed that such comments were deeply offensive and amounted to racial stereotyping.

How can we avoid issues of political correctness whilst acknowledging harms taking place within minority groups and implementing protective measures for victims who have courageously called out the abuse? To address HBA society needs to move beyond the attachment of culture-informed labels and focus on working with communities to hold to account the abusive actions by individuals. The notion of self-policing by minority communities has been widely documented, from challenging women as to their dress code in the street, strategic surveillance through networks such as mini cab and restaurant workers and family members, to hiring 'bounty hunters' to ensure 'izzat' or honour is maintained. As a result, this reinforces a false sense of security, if one complies, and an environment of fear if one does not. We have also seen how communities organise themselves to protect their beliefs and way of life, which in itself is not problematic. However, where the construct of certain groups or individuals within that community hold the view that cultural values and beliefs supersede all else, there are real dangers that the propagation of self-policing will continue and be viewed as an accepted norm.

\section{Who's policing whom?}

Where women and girls are typically viewed as being the 'holders' of family honour, in communities where there is a prevalence of HBA it can lead to a reluctance to publicly implicate family members, particularly where primary carers and siblings are involved or where duress or pressure is placed on the individual for non-disclosure. That said, we cannot rule out the role of women who may incite or actively participate in acts of violence or abuse performed due to [so called] honour (Dyer, 2015, p7). Moreover, it is not uncommon for siblings (male or female), cousins or extended family members to be identified by the 'council' to undertake acts of abuse as a means of compliance and duty, to demonstrate loyalty and also as a means of protecting themselves and/or the 'council' who are usually, but not always, senior members of the family. By recognising the role of women in communities, and therefore managing the behaviours of other women and girls, we can see how this aids the continuation of gender inequalities that act as a driver for harmful practices. Mothers who, out of fear or need for acceptance work, against the safety of their daughters, aunties who seek validation or status within the community, or grannies who could be the main perpetrators based on lived experiences. This is why mediating with family members is gravely discouraged, as even those who appear to be supportive may be (directly or indirectly) complicit or active in the abuse, or indeed at risk.

To explore this further, we can draw upon the Panopticon theory, first introduced by the philosopher and social theorist, Jeremy Bentham in the 18 th century. Panopticon is a type of institutional building (prison) with a built-in system of behavioural control. By developing a tower at the centre of the construct, this allows the watcher within the tower to look out but not be seen by those being viewed. Those being viewed remain unaware of who is watching them, aware only that they are being observed and a behavioural report will result in them being rewarded or penalised. Whilst this model has been adapted by multiple 
Vol. 8, No. 1, 81-90.

authors, it is Foucault's approach that explores the relationship between systems of social control and the power/knowledge dynamic; that is, power and knowledge is derived from observing others. As such, the power dynamics of the 'all seeing eye' ensures compliance based on fear and the unknown. This is particularly useful when looking at the application of this theory to communities that adhere to codes of honour.

This metaphor can explain why women regulate the behaviour of other women, not only to gain a sense of power in an otherwise male-dominated social construct, but also as a means of self-protection and preservation of other females, to ensure any breaches or perceived breaches of 'honour' are minimised to reduce risk or retaliation. In a digital age, this approach of always being seen but not knowing who is viewing you is all the more apparent, through surveillance of thoughts, dress, actions and behaviour using the medium of social media as the tower.

The notion of maintaining the family 'honour' often supersedes the actual needs and risks faced by the individual, as this is seen as being of 'less importance' than the breach or perceived breach of family codes of conduct (The Independent, 2014). Victim blaming is a common technique used to justify the actions of abusers, while communications amongst women in the community often involve questioning 'what did she do?' rather than 'why did they do that to her?' In doing so, it is easier to validate harmful behaviour by pointing the finger at 'her', rather than reflecting on the behaviour of those who have, or threatened, to cause harm. As such, the stigma and taboo around disclosure of abuse leading to disownment extends beyond the immediate family and community, and is often seen as a lifelong punishment for 'non-conformist' behaviour perceived to be brought on by the individual, rather than the actions of perpetrator(s).

\section{The future of policing $H B A$}

The pandemic has highlighted many challenges to policing and this has been reflected across the world when it comes to tackling gender-based crimes. Moreover, it has created an opportunity for the police to re-evaluate its role and powers to safeguard some of the most vulnerable members of society. We know that the police cannot tackle these issues alone; they play a significant but singular part in the wider criminal justice system. This is where the community must also take a stand through collective responsibility, to remove the concept of 'other' in order to fully address harmful practices and place the needs of survivors and victims at the heart of cultural and societal values.

Strategic development - a long-term policing strategy for tackling harmful practices must be balanced, not only to appropriately assess and respond to these crimes, but also to invest in the recovery stage, which is often long-term, requires dedicated resources, support, and ongoing safeguarding and risk management - a role that typically falls to nonstatutory services such as NGOs. As the role of policing during the pandemic continues to evolve, so does the need to be more agile and alert in safeguarding victims. We must also acknowledge the changes taking place in practising communities where these gendered crimes are being committed/performed. Domestic 'cutting' is continuing FGM practices, while forced marriages abroad now have longer planning times, all the while instilling dread. Even a request to take a walk or exercise can be viewed as being 'dishonourable'.

Reduction in community engagement has meant that harmful practices are taking place in plain sight, whilst the limitations in reporting these crimes become even greater when a person is living with the perpetrator(s), resulting in victims having to stay hidden in the shadows. Where no two HBA cases are the same, a one-size-fits-all approach will prove to be ineffective and cannot account for multiple variables based on risk of harm and the needs of the victim. It is not enough to simply scratch the surface by raising awareness - a concerted and strategic effort must be actualised, informed by research, data and experts, and reviewed 
regularly. This is particularly relevant when dealing with cases that feature female spouses entering the UK for the purpose of marriage, who are often equipped with little to no knowledge of their rights in a new country, do not know where to go to access support, nor have the opportunity to safely speak out against abuse inflicted by the family and/or community. More needs to be done to remove the barriers for women with No Recourse to Public Funds (NRPF), particularly where language is an issue. Failure to do so means inability to access justice and feeds into fears of being treated as a 'crimigant' (criminal migrant) upon disclosure (Bowling et al, 2003). Many women face the possibility of deportation and being penalised for calling out these hidden crimes, and report experiences of inadequate response from the police.

Strong leadership - policing still needs to do more to ensure leadership is embedded across all levels of all forces. Doing so will not only demonstrate the commitment by the police to take a zero-tolerance approach to harmful practices, but also send a message to practising communities that these hidden harms have no place in society. Lessons can only be learnt when mistakes are acknowledged and actions are taken to enable accountability and increase trust. Leadership in policing is seen in the way retired DCI Caroline Goode led on the Banaz Mahmod investigation and embedded organisational change as to the way the police respond to honour-related crimes, which introduced the 'One Chance Rule' - a thorough review of police failings and a heightened awareness of the risks associated with these crimes. The NPCC's recommendation that all forces should hold subject matter experts, or Single Point of Contact (SPOC) leads who are trained in harmful practices, may go some way to addressing the gaps in knowledge within policing, but it is not a magic bullet and requires long-term investment to ensure sustainable, dedicated resources are fully funded to reduce the 'postcode lottery' response of forces not meeting the levels of preparedness to address honour based abuse, as indicated in the 2015 HMRC report.

Training and recruitment - lack of training remains the single biggest issue cited by officers dealing with honour abuse related cases. Many who 'stumble' across such cases have no previous experience or understanding of the cultural issues and risks faced by the victim, witness or survivor. Notably, the lack of policing resources to manage such highrisk cases, and the fast pace of changing priorities, makes this form of crime all the more challenging, particularly where there are competing priorities faced by the police during the pandemic. Where cultural awareness training has arguably brought about little change over the years, its limitations will continue to result in victim(s) feeling unsupported. Lack of understanding of the victim's needs will continue to negate the pressures they face by family and community members to recant or disengage to preserve the notion of 'honour' and minimise the long-term impacts of being ostracised/disowned. Arguably, a new approach is required to improve cultural understanding whilst being mindful of oversimplifying or further alienating communities who already have a distrust of, or low expectations of, policing responses. Equally, lack of police training and cultural awareness is favoured by perpetrator(s) who can use officers' fears of political correctness to vindicate their actions and beliefs, in the knowledge that any challenges to cultural norms can be countered with accusations of racism.

The development of the Police Education Qualification Framework (PEQF) pathway is a timely development and may go some way to address consistency of professional standards, but it must also attract recruitment from wider communities with cultural or lived experiences, and every officer should be encouraged to challenge harmful practices regardless of race, gender or background, and with the full support of their senior and leadership officers.

Bates (2020) rightly calls for policing to distinguish HBA from other cases of domestic and intimate partner abuse. In doing so she also warns of the danger of using high profile 
Vol. 8, No. 1, 81-90.

honour killing cases, as a means of 'exoticizing HBA as something "othering," and polarising it from mainstream forms of domestic and intimate partner abuse, that negates all honour related abuse'. This risks oversimplifying BAME women's experiences, which could lead to creating a 'collective victimhood' that deliberately omits the very different experiences they face (Thiara \& Gill, 2010).

HBA is vastly under reported and places victims and witnesses at risk of significant harm. It can be directed to and perpetrated by men as well as women, and age, religion and culture are not, in themselves, determining factors. This is why it is imperative that the police get the basics right, such as accurate flagging on PNC, correctly spelling names on Orders, enhancing existing multi-agency approaches, intelligent information sharing, engaging with subject matter experts at key investigative stages and recognising the need for long-term support. In recognising that key areas of policing need to be better prepared to respond to such cases, this will increase the confidence of victims and survivors to come forward, in the knowledge that standards and mechanisms are in place to ensure effective informed safeguarding processes. When we are dealing with high-risk cases, we are in effect operating in 'homicide prevention' mode and need to disrupt high-harm perpetrators of domestic abuse from repeat offending on the same, or new, victims. Moreover, inclusive, balanced and considered communications and actions are required to bring harmful practices out of the shadows and be addressed as crimes, irrespective of fears of cultural insensitivities that have, and continue to, hinder progress, and to disrupt abuse based on power and control. Failure to invest in training, leadership and strategic development will mean we continue to question the effectiveness and legitimacy of the police's ability to safeguard and protect victims and survivors of HBA, particularly from BAME communities, many of whom already feel unheard and unprotected due to perceived gendered and cultural inequalities that exist within policing and within their communities.

\section{Note}

${ }^{1}$ Polly Harrar is Founder of The Sharan Project, a registered charity (England and Wales) supporting South Asian Women in the UK who have been affected by abuse or persecution, including forced marriage, honour abuse, dowry violence, domestic abuse, disownment and cultural conflict. As a strategic leader, she is the joint Chair of the London Harmful Practices Group led by the Metropolitan Police, member of the Home Office National Oversight Group and the Forced Marriage Partnership Board within the Foreign and Commonwealth Office and Home Office, and an advisory member for the Women's Interfaith Network. She is a recognised Expert Witness on forced marriage and honour based abuse and has an extensive understanding of the wide range of harmful practices faced by BAME women and children, and can regularly be heard speaking on these matters at a national and local level and through mainstream media. Polly.Harrar@sharan.org.uk

\section{References}

Bates, L. (2020) Honor-based abuse in England and Wales: 'Who does what to whom?' [online] https://journals.sagepub.com/doi/full/10.1177/1077801220952168. Accessed 13.12.2020.

BBC (2011) Jack Straw criticised for 'easy meat' comments on abuse [online] https://www. bbc.co.uk/news/uk-12142177. Accessed 14.2.21.

Bowling, B., Parmar, A. and Phillips, C. (2003) Policing Ethnic Minority Communities. In Newburn, T. (ed.) Handbook of policing. Willan Publishing: Devon, UK, pp. 528-555.

Dyer, E. (2015) Honour Killings in the UK. Henry Jackson Society pdf. [online] HonourKillings-in-the-UK.pdf (henryjacksonsociety.org) Accessed 14.2.21. 
Independent Inquiry into Child Sexual Abuse (2017) [online] https://www.iicsa.org.uk/ Accessed 14.2.21.

Inquiry meets with BAME women organisations to promote the Truth Project (2017) [online] https://www.iicsa.org.uk/news/inquiry-meets-bame-women-organisations-promote-truthproject Accessed 14.2.21.

Justice and Safeguarding at NTT DATA (2021) [online] https://uk.nttdata.com/documents/ digital-policing-at-ntt-data.pdf Accessed 14.2.21.

Le Roux, E., Bartelink, B.E. and Palm, S. (2017) What is the harm in 'harmful traditional practices'? [online] https://assets.publishing.service.gov.uk/media/5c7d 541e4ofob6o3d7852921/ PB_What_is_the_harm_So2_18Dec17.pdf Accessed 14.2.21.

Police 'let down' honour killing victim (2008) [online] https://www.business-live.co.uk/ economic-development/police-let-down-honour-killing-3960985 Accessed 14.2.21.

Reuters (2011) Straw in row over Pakistani men sex abuse comments [online] https://www. reuters.com/article/uk-britain-straw-abuse/straw-in-row-over-pakistani-men-sex-abusecomments-idUKTRE7071E620110108 Accessed 14.2.21.

Rosenbaum, D.P. (2002) Evaluating multi-agency anticrime partnerships: Theory, design, and measurement issues. Page 178 [online] https://www.researchgate.net/publication/ 228935598_Evaluating_multi-agency_anti-crime_partnerships_Theory_design_and_meas urement_issues Accessed 14.2.21.

Sentencing - Ancillary Orders (2019) The Crown Prosecution Service [online] https://www. cps.gov.uk/legal-guidance/sentencing-ancillary-orders Accessed 14.2.21.

The Huffington Post (2014) Tom Winsor, Chief Inspector of Constabulary, says 'alternative' policing is being administered in some parts of Britain [online] https://www.huffingtonpost. co.uk/2014/o1/18/tom-winsor-police-minorities_n_462188o.html Accessed 14.2.21.

The Independent (2014) 'Shunned, beaten, burnt, raped: The dowry violence that shames Britain' [online] https://www.independent.co.uk/news/uk/crime/shunned-beaten-burntraped-dowry-violence-shames-britain-9803009.html Accessed 15.10.14.

Thiara, R. and Gill, A.K. (2010). 'Understanding violence against South Asian women: What it means for practice'. In R.K. Thiara \& A.K. Gill (Eds.), Violence against women in South Asian Communities. Jessica Kingsley, pp. 29-54.

Wodon, Q., Malé, C. and Onagoruwa, A. (2020) A simple approach to measuring the share of early childbirths likely due to child marriage in developing countries. Forum for Social Economics, 49(2), pp. 166-179. 